\title{
An Introductory Course in Practical Systems Engineering
}

\section{Dr. Michael A. Swartwout, Saint Louis University}

Dr. Michael Swartwout is an assistant professor of Aerospace and Mechanical Engineering at Saint Louis University. His research is on the design and operation of low-cost, capable space systems. He has sponsored many student-built space projects, with two due to launch in 2013 and 2014.

\section{Dr. Sanjay Jayaram, Saint Louis University, Parks College of Eng.}

Dr. Sanjay Jayaram is an associate professor in the Aerospace and Mechanical Engineering Department of Saint Louis University. He obtained his Ph.D. in Mechanical Engineering from University of Central Florida in 2004. He teaches control systems/mechatronics, space systems engineering, and astronautics related courses as well as engineering sciences courses. He has published several peer reviewed journal and conference papers in these areas. His research areas are space systems, robust fault tolerant control, nonlinear control, adaptive control, small spacecraft design, high performance spacecraft components, mechatronics, real-time health monitoring, and diagnostic methodology. 


\title{
An Introductory Course in Practical Systems Engineering
}

\begin{abstract}
$\underline{\text { Abstract }}$
Good systems engineering is essential for the effective design, fabrication, testing and operation of complex systems such as spacecraft. However, teaching good systems engineering to undergraduates is often viewed as either impossible (because it must be developed in real, professional settings) or impractical (because it requires sophisticated tools that are best covered at the Masters level). While we do not dispute that becoming a good systems engineer requires years of practical experience and solid technical fundamentals, we believe that undergraduates are capable of learning some of the fundamental tools and applying them to relevant projects.
\end{abstract}

We have developed a two-semester course sequence for entry-level engineering students (i.e. freshmen and sophomores). The first semester is a 2-credit course, consisting of a 1-credit classroom lecture and a 1-credit laboratory element; the second semester is a 1-credit laboratory course. The classroom portion is a seminar-style presentation of systems engineering tools such as requirements flow, work breakdown structures, design drivers, trade studies and risk assessment. For the laboratory portion of both semesters, the students apply these tools in ongoing student-led space projects: high-altitude balloon experiments, microgravity tests and a series of student-built spacecraft. We believe that blending a subset of systems engineering tools with small but real-world, achievable missions will give them practical experience.

In this paper, we will review the typical approaches to giving students hands-on project experience: informal clubs, participation in national competitions, paid internships and coursebased projects. We will assess the strengths and shortcomings of these methods, motivating our approach to the course. We will provide an outline of our two-semester space projects course and the specific objectives it will meet. We will review the results of the course to date, and provide short-term assessment of the courses' usefulness.

\section{$\underline{\text { Introduction }}$}

Modern aerospace systems can be quite complex, with hundreds or thousands of electrical, mechanical and chemical elements working together to achieve a challenging objective. In fact, these systems are complex because of their challenging objectives: aircraft and spacecraft must transport people, cargo and time-sensitive data through extreme environments and do so with very high reliability. Simple solutions are often insufficient, and yet the complex solutions require years of development and tens of millions of dollars (or more) - and still run a high risk of failure.

In the design and fabrication of aerospace vehicles, the role of the systems engineer is to ensure that a vehicle is created that meets the mission objectives within the constraints of cost, schedule and risk. Good systems engineers bring great value to their organizations, but universities are not yet producing good systems engineers. [1,2] Many schools offer graduate-level programs in systems engineering, which focus on computational tools and management strategies. These tools are essential to the role, but the tools are only one aspect of the job. Moreover, the authors 
believe that undergraduates can and should receive better training in the core principles of systems engineering.

The challenge with teaching the "core principles" is that professional engineers usually acquire this knowledge through experience, the painful learning from failures and, occasionally, successes. In fact, while he was NASA Administrator, Mike Griffin flatly stated that universities were not equipped to teach systems engineering, and that students should enter the workforce as soon as possible in order to learn to become good systems engineers. [3,4] One of the cited benefits of the Air Force-sponsored University Nanosat spacecraft competition is that it gives students the chance to "fail" on their own, student-built satellites, and thus spare their future employers from having them learn the lesson on the job. [1] We applaud the University Nanosat Program's approach; we want to formally integrate it into the curriculum at our university.

We believe that hands-on, student-led projects provide a unique opportunity to provide relevant training in systems engineering, project management and related disciplines. The use of engineering failures as teaching tools have been implemented elsewhere [5, 6, 7]; we are interested in creating opportunities for students to experience project failures - and then overcome those failures.

We have developed a two-semester course sequence for entry-level engineering students (i.e. freshmen and sophomores), giving them a chance to learn from failures (and success). The first semester is a 2 -credit course, consisting of a 1-credit classroom lecture and a 1-credit laboratory element; the second semester is a 1-credit laboratory course. The classroom portion is a seminarstyle presentation of systems engineering tools such as requirements flow, work breakdown structures, design drivers, trade studies and risk assessment. For the laboratory portion of both semesters, the students apply these tools in ongoing student-led space projects: high-altitude balloon experiments, microgravity tests and a series of student-built spacecraft. We believe that blending a subset of systems engineering tools with small but real-world, achievable missions will give them practical experience.

We chose to adopt a regular course structure over alternate approaches for four reasons: a regular, grade-based course provides student incentive (and credit) for completing assignments; the course provides an artificial schedule for projects that could otherwise continue indefinitely (i.e., the course creates midterm and final-exam milestones); having the course emphasizes to our students the value we place on hands-on learning; and the course serves as a recruiting tool for students outside the school of engineering and for those considering admission to our university.

In this paper, we will review the typical approaches to giving students hands-on project experience: informal clubs, participation in national competitions, paid internships and coursebased projects. We will assess the strengths and shortcomings of these methods, motivating our approach to the course. We will provide an outline of our two-semester space projects course and the specific objectives it will meet. We will review the results of the course to date, and provide short-term assessment of the courses' usefulness. 


\section{Alternate Approaches}

We are by no means the first school to implement hands-on activities. A wide range of approaches have been implemented, including clubs, national competitions, internships and course-based projects. We will examine each in turn.

We define club activities as any student activity that does not involve course credit or the structure of a national competition. Clubs are among the most common implementation, as they can be easily created and structured to fit the needs and interests of the participants. This flexibility is also a challenge, as it can be difficult to maintain focus and motivate volunteer participants to do the difficult but necessary jobs (e.g., documentation). Similarly, the openended nature of the club may cause projects to spread over years, which reduces the excitement for new students; they would rather build their own device than incrementally modify one that is "almost finished".

National Competitions are similar to clubs, except that the student group has an externallydefined set of objectives. The SAE Formula Car, the AIAA and SAE Design/Build/Fly competitions, and the Air Force University Nanosat Program are examples. In each, a national organization sets the rules of competition, and the students work within those guidelines. There are several advantages to national competitions: external deadlines are excellent motivators for even volunteers, the external rules help train students in best practices, and the programs are set on yearly cycles, which helps create new learning opportunities for incoming students.

Depending on the program, the project may not fit the educational objectives of a hands-on systems engineering program.

Internships are the standard way to "teach" systems engineering, by giving students practical experience in the workforce. Students learn as they participate in real projects alongside professional engineers. The disadvantage to internships is that the educational benefit is only provided for the few students selected for such programs.

In many respects, course-based projects are a formalization of the student club, where the students earn course credit for participating in the design process. This approach has the advantage of creating obvious motivation for student participation (grades), as well as allowing the material to be tailored to the needs. Often course-based projects and national competitions are merged, with capstone design courses geared towards a national competition. The obvious disadvantage to the course-based project is the effort required by the instructors to properly set up and manage the course.

Despite the effort required, we chose the course-based project for our hands-on training. We wanted to have the motivation afforded by course credit, as well as the natural deadlines of final exams to set and enforce schedule. We also liked the publicity that comes with a course; students outside of the major with an interest in aerospace projects will find it in the course catalog. We also identified many hands-on projects that would fit within the semester scope. 


\section{Course Outcomes and Outline}

The course is arranged in a two-semester sequence; the first involves a 1-credit lecture and 1credit lab, and the second is just the 1-credit lab. The outcomes of the both courses are:

1. Ability to use system engineering tools to manage cost, schedule, performance and risk on a real-world multidisciplinary project.

2. Ability to work in multidisciplinary teams.

3. Ability to build, test and operate space and space-equivalent systems.

We will assess these outcomes through a series of reviews and demonstrations. Students will formally present their work in weekly status reports as well as pre-flight reviews. They will build and test their projects, evaluate the tests, and then participate in a flight-equivalent demonstration.

In the lecture portion, we will review the following topics:

1. Contemporary space missions

2. Spacecraft design lifecycle

3. Requirements flow

4. Work Breakdown Structure

5. Scheduling and Critical Path

6. Design Process and Design Drivers

7. Risk Assessment

8. $\quad$ Trade Studies

9. Verification of Requirements

10. Project Management

Students will have weekly assignments to assess learning.

\section{$\underline{\text { Pilot Program }}$}

A pilot program is being run in Spring 2013 involving 5 students already participating in the satellite project. For this introductory offering, we will focus on the existing space projects at the university. Students will participate in environmental testing and functional demonstrations of the student satellites. Students will conduct vibration, thermal vacuum, deployment and end-toend functional demonstrations of the spacecraft under construction. They will perform pre- and post-reviews before each of these activities. They will write software, integrate hardware, sensors and other electronics, and assess the performance of the system against the requirements. We anticipate difficulties and even failures to arise during the process, and thus the students will lead reviews, identify modifications, implement changes and re-test.

At the time of this submission, we are halfway through the pilot program. The students have successfully drawn up test procedures and worked to acquire the parts necessary to conduct tests. They have coordinated with the Air Force Research Laboratory to conduct environmental testing, and will be traveling there in two weeks. We are satisfied with the learning and progress 
so far. The primary challenge is that the students in the pilot program are dependent on students outside the program to provide key parts of the spacecraft (especially the primary payload and flight software). For the full implementation, we will ensure that the entire project is under the control of the students in the class.

\section{Planned Modifications for Next Offering}

Contingent on the results of the pilot program, we intend to formally introduce the class in Fall 2013, opening it to students in the entire university. In addition to the satellite work, we will expand to cover additional projects: high-altitude balloons payloads and spacecraft operations.

We will track student participation in terms of the numbers who stick around to contribute to the project after the course is completed. We will also track how many students join from outside the college of engineering; at present, all of our students are from inside the college.

\section{$\underline{\text { Summary and Conclusions }}$}

Hands-on projects provide an excellent opportunity to teach students the practical realities of systems engineering, and to teach them how to effective use the available tools to maximize positive outcomes. Course-based projects provide a means to recruit new students, train them, and retain them in the project. The challenge is to scope projects to fit within academic constraints. We have identified a candidate approach for second-year students to participate in short-term, flight-focused activities. We will assess the pilot program during the Spring of 2013.

\section{$\underline{\text { References }}$}

[1] G. Hunyadi, J. Ganley, A. Peffer, and M. Kumashiro, The University Nanosat Program: An Adaptable, Responsive and Realistic Capability Demonstration Vehicle. IEEE Aerospace Conference Proceedings, vol. 5, 2004, pp. 2850-2858.

[2] AIAA, Survey of Aerospace Engineering Training 1992-2002, conducted by Abacus Associates, 2003.

[3] J. Bauman. NASA chief justifies cuts during session at USU. Deseret Morning News, August 15, 2006. Cited from online version: http://www.deseretnews.com/article/1,5143,645193239,00.html?pg=2

[4] M.D. Griffin, "How Do We Fix Systems Engineering", 61 ${ }^{\text {st }}$ International Astronaut Congress, Prague, Czech Republic, 2010.

[5] H. Petroski, "To Engineer is Human: The Role of Failure in Successful Design", St. martin's Press, New York, 1985.

[6] H. Petroski, "Design Paradigms: Case Histories of Error Judgment in Engineering", Cambridge University Press, Cambridge, 1994.

[7] D. Lanning, W. Lestari, S. Waterhouse, "A Laboratory-Based Course in Aerospace Engineering Failure", Proceedings of the 2010 American Society for Engineering Education Zone IV Conference. 